\title{
O atendimento ao aluno especial em tempos de pandemia: espaços ocupados?
}

\author{
Care to special students in times of a pandemic: busy spaces?
}

La atención al alumno con discapacidad en tiempos pandémicos: ¿espacios ocupados?

Recebido: 31/07/2021 | Revisado: 05/08/2021 | Aceito: 07/08/2021 | Publicado: 13/08/2021

\author{
Carolina Menezes de Brito Reis \\ ORCID: https://orcid.org/0000-0003-1886-6630 \\ Instituto Federal de Educação, Ciência e Tecnologia de Minas Gerais, Brasil \\ E-mail: profcarolinareis@gmail.com \\ Vagner Luiz da Fonseca \\ ORCID: https://orcid.org/0000-0003-3237-6064 \\ Instituto Federal de Educação, Ciência e Tecnologia de Minas Gerais, Brasil \\ E-mail: vagner_luizfonseca@yahoo.com.br \\ Niltom Vieira Junior \\ ORCID: https://orcid.org/0000-0003-1077-8302 \\ Instituto Federal de Educação, Ciência e Tecnologia de Minas Gerais, Brasil \\ E-mail: niltom.vieira@ifmg.edu.br
}

\begin{abstract}
Resumo
A pandemia do COVID-19 surpreendeu abruptamente a população mundial, transformando todos os cenários das relações humanas. A letalidade do vírus e a rapidez com que se dissemina obrigou países por todo o globo terrestre a promover os chamados lockdowns. A sociedade precisou se reinventar em todas as áreas. As pessoas tiveram de modificar sua forma de trabalho, sua vida pessoal e também sua relação com o outro. Na escola, não foi diferente. $\mathrm{O}$ vírus SARS-COV-2 causou um impacto tão grande que a educação precisou ser vista de outro ângulo e se atualizar. A partir disso, este trabalho realiza uma breve revisão da literatura sobre o atendimento do aluno especial no ano pandêmico de 2020 e discute o espaço do aluno especial, seja na sociedade ou em âmbito físico e escolar, uma vez que o ensino remoto trouxe uma perspectiva de inclusão com base no ensino presencial. Por fim, ressalta-se a necessidade de repensar os espaços físicos e virtuais ocupados pelos alunos de inclusão, a fim de tornar este processo real e acessível mesmo em períodos extremos, como durante a pandemia do COVID-19.
\end{abstract}

Palavras-chave: Covid-19; Educação especial; Inclusão; Ensino.

\begin{abstract}
The COVID-19 pandemic abruptly surprised the world population, transforming all scenarios of human relations. The lethality of the virus and how quickly spreads, forced countries around the globe to promote the so-called lockdowns. The society needed to reinvent itself in all areas. People had to change their way of working, their personal life and also their relationship with each other. In the school wasn't different. The SARS-COV-2 virus caused such an impact that education had to be seen from another angle and update. Based on this, this work performs a brief review of the literature on the care of special students in the pandemic year of 2020, and discusses the space of special students, whether in society or in the physical and school context, since remote learning brought a perspective inclusion based on classroom teaching. Finally, it emphasized the need to rethink the physical and virtual spaces occupied by the inclusion students, in order to make this process real and accessible even in extreme periods, such as during the COVID-19 pandemic.
\end{abstract}

Keywords: Covid-19; Special education; Inclusion; Teaching.

\begin{abstract}
Resumen
La pandemia de COVID-19 sorprendió abruptamente a la población mundial, transformando todos los escenarios de las relaciones humanas. La letalidad del virus y la rapidez con la que se propagó obligó a los países de todo el mundo a promover los llamados lockdowns. La sociedad tuvo que reinventarse en todos los ámbitos. Las personas tuvieron que cambiar su forma de trabajar, su vida personal y también su relación con los demás. En la escuela, no fue diferente. El virus SARS-COV-2 tuvo tal impacto que la educación tuvo que ser vista desde otro ángulo necesitando actualizarse. A partir de esto, este trabajo realiza una breve revisión de la literatura sobre el cuidado del estudiante especial en el período de la pandemia a partir de 2020 y analiza el espacio del estudiante especial, ya sea en la sociedad o en el contexto físico y escolar, ya que la enseñanza remota trajo una perspectiva de inclusión basada en la enseñanza presencial. Por último, se hizo hincapié en la necesidad de repensar los espacios físicos y virtuales que ocupan los estudiantes de inclusión, con el fin de hacer que este proceso sea real y accesible incluso en períodos extremos, como este de la pandemia de COVID-19.
\end{abstract}

Palabras clave: Covid-19; Educación especial; Inclusión; Enseñanza. 


\section{Introdução}

Há pouco mais de um ano a pandemia do COVID-19 transformou a dinâmica escolar tal radical e tragicamente em esfera mundial. Desde então, o povo brasileiro tem sido obrigado a conviver com as desventuras deste período que insiste em perdurar. Devido esse contexto, mudanças abruptas puderam ser notadas, como por exemplo, a passagem do ensino presencial para o ensino remoto.

A comunidade escolar (diretores, gestores, professores, pais/responsáveis, alunos) se viu obrigada a pesquisar, descobrir, conhecer e manusear ferramentas e recursos tecnológicos desconhecidos ou raramente usados, até então. Além disso, teve que aprender a contornar dificuldades, como a falta de acesso à internet, os baixos recursos financeiros e a falta de comunicação com os pais. Neste contexto, é importante destacar a fundamental parceria existente entre os gestores escolares, professores e pais/responsáveis de alunos, para que, em meio a toda incerteza, dificuldades e desafios houvesse a conscientização a respeito da necessidade da manutenção da oferta de educação de qualidade aos seus filhos, mesmo que de forma remota.

Devido à pandemia do COVID-19, o ano de 2020 foi marcado pelo cancelamento das atividades presenciais em escolas do Brasil inteiro e, no caso de algumas escolas particulares, o tão famoso ensino híbrido, uma tentativa de minimizar as perdas educativas. O cenário de isolamento social trouxe a necessidade de adotar medidas excepcionais para a continuação dos mais variados tipos de atividades, conforme as necessidades e o ritmo de vida social. Não diferente, as escolas também tiveram que se adaptar para o desenvolvimento de atividades não presenciais e para garantir ao aluno seu direito de aprendizagem. No contexto do processo de ensino aprendizagem "a falta de recursos tecnológicos destinados à educação acaba por inviabilizar ainda mais o acesso à educação durante a pandemia, se antes a dificuldade estava em chegar até as escolas, agora muitos alunos vão enfrentar o fato de não terem recursos suficientemente para acompanhar as aulas online e executar as atividades solicitadas" Avelino e Mendes (2020, p. 58).

Neste sentido, para manter as atividades em funcionamento durante o período pandêmico do COVID-19, que obrigou o distanciamento social e se arrasta até o presente momento, foi necessária a suspensão das aulas presenciais, o que, de modo surpreendente, fez com que os professores tivessem que utilizar, principalmente, os meios digitais para dar continuidade ao ensino. Conforme (De Sousa Oliveira, 2020), essas tecnologias não eram a realidade de alguns professores e, muito menos da maioria dos pais/responsáveis dos alunos.

Nota-se, portanto, como a escola no Brasil se viu impactada com o surgimento da pandemia. As redes escolares começaram a se organizar para, de forma remota, continuar a oferta do ensino, enfrentando desafios antes inimagináveis. O ensino remoto no Brasil foi regulamentado pela Lei $\mathrm{n}^{\circ} 14.040$ (Brasil, 2020a), que estabeleceu as normas educacionais excepcionais que deveriam ser adotadas enquanto durasse o estado de calamidade pública, prevendo que tais estratégias fossem adotadas pelos sistemas de ensino no transcurso do ano letivo prejudicado pela pandemia (Brasil, 2020a).

Em 28 de abril de 2020, o Conselho Nacional de Educação (CNE) havia emitido o parecer n 5 (Brasil, $2020 b$ ) visando reorganizar o calendário escolar e cômputo das atividades não presenciais para fins de cumprimento da carga horária mínima anual. Este documento esclarece que as atividades pedagógicas não presenciais devem ser aplicadas a alunos de todas as etapas, níveis ou modalidades de ensino e também aos alunos da educação especial (Torres \& Borges, 2020, pp. 825-826). Nota-se, com esse parecer, um único objetivo, conforme Souza e Dainez (2020, p.3) o ensino remoto emergencial anuncia-se como uma estratégia para manter o período letivo. A preocupação, notadamente, centrou-se na necessidade do cumprimento dos dias letivos e da carga horária.

Há, erroneamente, a ideia de que o ensino remeto imposto pela condição pandêmica se assemelha ao ensino a distância. Sabe-se, porém, que as estratégias utilizadas no ensino a distância possuem processos diferentes até a chegada do material ao aluno da Educação a distância, tais como gravações de aula, preparo de materiais e a adequação a uma realidade 
que se difere, certamente, da educação presencial. Sendo assim, o ensino remoto foi uma alternativa para minimizar as perdas educacionais dentro do contexto incerto da pandemia, porém, que utiliza estratégias próprias para o ensino.

A sala de aula foi substituída pelas redes sociais digitais de comunicação, a saber, o facebook, o whatsapp, o telegram, ou por ambientes virtuais de aprendizagens específicos contratados por um ou outro estado, ou município, bem como por aulas televisionadas organizadas por algumas Secretarias de Educação de alguns estados e municípios.

As mudanças no sistema educacional tiveram que ser realizadas rapidamente, de sorte que, de um dia para o outro, os professores precisaram transpor conteúdos e adaptar suas aulas presenciais para plataformas on-line com o emprego das Tecnologias Digitais da Informação e Comunicação (TDIC), sem preparação para isso, ou com preparação superficial, também em caráter emergencial (Rondini, Pedro \& Duarte. 2020, p. 43).

Vale ressaltar, ainda, que a inserção das TDIC nos contextos e nas práticas escolares ainda é um entrave na realidade nacional; a infraestrutura quase sempre precária e a formação docente deficitária são variáveis importantes que interferem diretamente em uma utilização crítica, intencional e produtiva das tecnologias (Braga, 2018; Thadei, 2018). Novamente, o ensino remoto devido esse contexto pouco se relaciona com o ensino a distância, uma vez que até as aulas remotas procuraram adequar a sala de aula presencial para o modelo a distância como maneira de minimizar as perdas escolares, no entanto esse modelo é improvisado e portanto ainda deverá ser avaliado quanto às consideráveis lacunas que tem causado no processo de ensino aprendizagem e os déficits impactantes que vem acarretando à vida e ao aproveitamento pedagógico dos alunos.

Na perspectiva Hodges et al (2020), (como citado em Rondini, Pedro \& Duarte 2020, p. 43), o ensino remoto emergencial difere da modalidade de Educação a Distância (EAD), uma vez que a EAD conta com recursos e uma equipe multiprofissional preparada para ofertar os conteúdos e atividades pedagógicas, por meio de diferentes mídias em plataformas on-line. Por outro lado, o intuito do ensino remoto não é estruturar um ecossistema educacional robusto, mas ofertar acesso temporário aos conteúdos curriculares que seriam desenvolvidos presencialmente no ensino regular. Desse modo, em consequência do período pandêmico, o ensino remoto emergencial tornou-se o principal modo de as instituições educacionais de todos os níveis de ensino manterem a oferta do ensino, ou seja, de forma temporária enquanto durar a pandemia.

Ainda em conformidade Hodges et al (2020), o planejamento pedagógico em situações atípicas exige resolução criativa dos problemas, demandando transposição de ideias tradicionais e proposição de estratégias pedagógicas diferenciadas para atender à demanda dos estudantes e professores (como citado em Rondini, Pedro \& Duarte (2020, pp. 43-44). Além disso, os referidos pesquisadores destacam que tais soluções podem ser duradouras, favorecendo, dessa forma, a resolução de problemas e paradigmas que até então pareciam insuperáveis.

As Universidades têm lutado pela educação por meio da tecnologia como uma forma de tornar acessível o ensino, principalmente onde há dificuldade para estudar em um polo mais desenvolvido. Com a pandemia do COVID-19, esta realidade se tornou ainda mais visível e disparou as desigualdades sociais por diversos motivos. No entanto, segundo apontam Rondini; Pedro e Duarte (2020, p. 47) as TDIC por si só não serão capazes de revolucionar a educação, porque, além da escolha adequada dos recursos que serão utilizados, é preciso adotar estratégias metodológicas assertivas, as quais promovam uma aprendizagem significativa por parte dos estudantes. Neste cenário, a Educação Inclusiva sofreu ainda mais os impactos, não somente educacionais como também do preconceito em relação aos alunos, muitas vezes vitimados pelos discursos capacitistas agravados pelo cenário hodierno.

Diante do contexto exposto, este trabalho tem como objetivo realizar uma breve revisão bibliográfica sobre o ensino remoto de alunos especiais durante o ano de 2020, período crítico da pandemia do COVID-19 e evidenciar como os espaços foram ressignificados perante a situação atual, que perdura em 2021. 


\section{Metodologia}

Este estudo foi realizado por meio de pesquisas bibliográficas em meio digital devidamente referenciadas, discussões em eventos acadêmicos acerca da inclusão dentro do contexto da pandemia do COVID-19 e pela experiência dos autores em realizar práticas pedagógicas durante este período conturbado e que ainda não se findou. Os alunos participantes do estudo, possuem necessidades especiais específicas, entre elas, Transtorno do Espectro Autista (TEA) e Transtorno de Processamento Auditivo Central (TPAC), além de outras comorbidades ainda sem laudo técnico. O espaço de realização se deu, inicialmente, em salas multifuncionais em uma escola particular da cidade de Belém do Pará, Brasil, onde a inclusão ocorre de forma assídua, porém, interrompida durante parte do ano de 2020 devido o surgimento da pandemia do coronavírus e o pouco conhecimento sobre suas consequências em caráter mundial.

De acordo com Artigo 27 da Lei 13.146/2015, estabelece como o Estatuto da Pessoa com Deficiência, pode-se depreender a seguinte compreensão:

A educação constitui direito da pessoa com deficiência, assegurados sistema educacional inclusivo em todos os níveis e aprendizado ao longo de toda a vida, de forma a alcançar o máximo desenvolvimento possível de seus talentos e habilidades físicas, sensoriais, intelectuais e sociais, segundo suas características, interesses e necessidades de aprendizagem. (Brasil, 2015, s/p).

Sendo assim, ainda que em contexto pandêmico e com a mesma preocupação que o mundo teve com os alunos regulares das escolas, o mesmo direito é estabelecido para aqueles que necessitam de um atendimento diferenciado e de qualidade para seguirem o processo formativo de aprendizagem corrente, adequado à realidade vivida por toda a comunidade escolar, para tanto o Parecer $n^{\circ}$ 5/2020 do CNE orienta:

As atividades pedagógicas não presenciais aplicam-se aos alunos de todos os níveis, etapas e modalidades educacionais. Portanto, é extensivo àqueles submetidos a regimes especiais de ensino, entre os quais os que apresentam altas habilidades/superdotação, deficiência e Transtorno do Espectro Autista (TEA), atendidos pela modalidade de Educação Especial. (Brasil, 2020, p.14).

Para realizar tal estudo, oriundo de estudos realizados durante o curso de pós-graduação em Educação Inclusiva, do Instituto Federal de Minas Gerais, foi necessário o intercâmbio de informações do Norte e Sudeste, uma vez que a pandemia atingiu a todos, mas de maneira diversa e de acordo com cada região, considerando suas peculiaridades. Portanto, ainda que não seja o alvo deste trabalho, é necessário ressaltar as desigualdades presentes entre as regiões geográficas em diversos aspectos, entre eles, o educacional, social e econômico. Para tanto, autores como Cury (s/a) e Loureiro, Rodrigues; Mattar (2020), além das respectivas legislações vigentes foram necessárias para a realização deste trabalho.

Considerando-se o próprio contexto da pandemia, a necessidade do distanciamento social, os cuidados e precauções sanitárias, este estudo apresenta caráter qualitativo, procurando reunir os principais trabalhos acerca do assessoramento ao aluno de inclusão neste período. Sendo assim, como afirma Pereira et al. (2018), observaram-se aspectos como os dados reunidos pelos pesquisadores para compor este trabalho; a descrição dos dados como informações e, naturalmente, a indução dos dados para a contribuição deste trabalho.

\section{Resultados e Discussão}

Para iniciar a discussão que aborda as revisões de literatura, é necessário contextualizar a realidade da educação inclusiva diante da pandemia do COVID-19. Loureiro, Rodrigues e Mattar (2020, p.1) realizam um trabalho de compilamento de artigos a respeito da inclusão realizada no Brasil. A princípio, citam: 
A escola inclusiva é um desafio para a sociedade, assumindo uma particular relevância durante a pandemia COVID19. Os alunos de origens vulneráveis foram particularmente afetados, incluindo crianças e jovens de famílias de baixo rendimento e monoparentais, imigrantes, refugiados, minorias étnicas e origens indígenas e aqueles com necessidades educativas especiais. (Loureiro, Rodrigues; Mattar, 2020, p.1)

Logo, percebe-se a discrepância de realidades entre, inicialmente, as regiões geográficas e, posteriormente, entre as realidades determinantes por cor, raça, sexo e religião. Estas questões não se tornam apenas relevantes como necessárias tanto para a compreensão do cenário pandêmico quanto ao abismo ainda mais evidenciado por toda a comunidade escolar durante este período. Profissionais da área de inclusão constantemente queixam-se do abandono dos alunos com necessidades especiais devido a esse contexto.

Ainda sobre a realidade dos alunos de inclusão, Neta; Nascimento e Falcão (2020) impactam as percepções ao mencionar "A invisibilidade dos invisíveis". Isto chama atenção para um problema recorrente onde os alunos são excluídos socialmente todos os dias e o tempo todo e mais ainda quando se trata de tecnologia ou aprendizado a distância.

Reiteramos, neste sentido, a importância das interações para o desenvolvimento e a aprendizagem que, segundo Vigotsky (1997), se dão com base nas relações e trocas estabelecidas no ambiente social mediatizado pela cultura. Portanto, a ausência de interações e vivências desfavorece o desenvolvimento dos alunos, em seu sentido mais amplo. No caso do desenvolvimento das pessoas com deficiência, Vigotsky (1997) destaca que é importante favorecer caminhos alternativos que possibilitem a superação das dificuldades dos alunos e contribuam para o seu desenvolvimento. No entanto, isso se apresenta como algo bastante desafiador, já que esses alunos encontram-se isolados e os momentos de planejamento que contemplem suas especificidades são mais escassos, dadas as condições a que as instituições e agentes de ensino estão submetidos. (Neta; Nascimento, Falcão, 2020, p.8).

Loureiro, Rodrigues e Mattar (2020) trazem a seguinte colocação a respeito das salas multifuncionais:

Os professores, a distância e em cada sala de aula estendida ou virtual, fizeram todos os esforços para manter a qualidade do ensino, reinventando estratégias e definindo novas dinâmicas, adequando-se às necessidades dos alunos, às contingências, às restrições e às potencialidades tecnológicas, adaptando-se, pouco a pouco, ao novo normal apoiado e mediado pelas tecnologias digitais. Nas salas de aula estendidas ou virtuais, aspetos como a possibilidade de colaboração, comunicação, partilha e socialização são essenciais, pelo que a capacidade de socializar é assumida como um factor crucial para uma aprendizagem colaborativa e para a construção de conhecimento (Loureiro; Bettencourt, 2014) (como citado em Loureiro, Rodrigues \& Mattar, 2020).

Além disso, Freitas; Trotta (2020) ressaltam que a tecnologia utilizada é fundamental na escolha de realização da inclusão e também na facilidade de acesso à aprendizagem, como exposto na citação abaixo.

[a] inserção de recursos tecnológicos nas salas de aula eram instrumentos facilitadores da aprendizagem e, durante a pandemia, se tornaram grandes aliados à educação. No entanto,ter a tecnologia não é suficiente, é preciso ir além. Vinte anos antes, o filósofo Pierre Lévy já chamava a atenção para essa questão. "Não basta estar na frente de uma tela, munido de todas as interfaces amigáveis que se possa pensar, para superar uma situação de inferioridade. É preciso, antes de mais nada, estar em condições de participar ativamente dos processos” (Lévy, 1999, p. 238). (Freitas, Trotta, 2020, p.1)

Entre diversos aspectos a serem ressaltados durante o período do COVID-19 estão os espaços de aprendizagem dos alunos especiais, situação que ficou prejudicada pela forma de transmissão do vírus. Logo, considerando as necessidades de cada aluno e os desafios enfrentados pelo professor, reitera-se, inicialmente, a empatia com todos nesse momento difícil.

Segundo foi possível observar, a educação especial demanda uma série de prioridades em relação ao atendimento especializado aos alunos e, também, um atendimento mais personalizado/individualizado se comparado às necessidades dos 
alunos de uma sala de aula regular.

Para melhor contextualizar a discussão, observou-se, também, alguns aspectos do trabalho realizado na Sala de Recursos Multifuncionais pelo olhar do professor que ali trabalha. Para o enriquecimento desta discussão, analisou-se o exposto no artigo, "Atendimento Educacional Especializado: aspectos da formação do professor", que foi publicado em 2017 no Caderno de Pesquisas, com autoria de Maria Silvia Pasian, Enicéa Gonçalves Mendes, Fabiana Cia.

$\mathrm{O}$ artigo mencionado trata de fazer uma análise sobre a situação dos professores que trabalham com alunos especiais, atendendo-os em salas de recursos multifuncionais - SRM. As pesquisadoras desenvolveram sua investigação por meio de questionário eletrônico respondido por mais de 1202 professores das SRM de vinte estados Brasileiros e mais de 150 cidades (Pasian; Mendes \& Cia, 2017).

Com base na pesquisa das autoras é possível observar, que dos 1202 professores que responderam ao questionário, uma parcela muito pequena se sente apta para o trabalho nas SRM (p.969). Isso explicita a necessidade de formar os professores que irão lidar com o público da SRM, visando melhorar não apenas a qualidade do atendimento, mas o desenvolvimento de estratégias eficientes que propiciem aos alunos AEE, a aprendizagem.

De acordo com a pesquisa, grande parte dos professores compreendem a função do AEE de complementar para os alunos com deficiência e TGD e suplementar para os alunos com AH/SD. Portanto, é necessário que os professores conheçam o material que elucida sobre o caráter do atendimento desse alunado, e também a legislação.

Outro dado interessante do trabalho é o de que, uma parcela muito grande de docentes disse não ter acesso aos documentos orientadores da SRM/AEE publicados pelo MEC (970). Ou seja, a maior parte dos professores desconhece e não entende os documentos que orientam suas práticas na SRM/AEE. No entanto, um fato bastante curioso foi que, boa parte desses mesmos professores respondeu estar preparada para atuar em todos os níveis de ensino. "É interessante salientar que os professores sentem-se preparados para atuar em todos os níveis, uma vez que as demandas para cada nível de ensino são bem diferenciadas (Pasian; Mendes \& Cia, 2017, p.971). Aspecto este, que para as pesquisadoras é contraditório pois outra pesquisa aponta que: "as principais queixas dos professores é a de atender vários alunos de níveis de ensino diferentes (Mendes et al., 2010; Pletsch, 2009, apud Pasian; Mendes \& Cia, 2017, p.971).

A pesquisa aponta para uma série de contradições entre as respostas dadas pelos docentes que atuam nas SEM e as reclamações que apresentam sobre as dificuldades do trabalho que realizam. O que para as pesquisadoras revela uma necessidade de se discutir sobre a formação tanto inicial, como continuada, desses docentes. "A formação do professor para trabalhar com o PAEE deve ser efetiva para capacitá-lo e especializá-lo para atender às necessidades educacionais dos alunos, favorecendo a inclusão escolar" (Pasian; Mendes \& Cia, 2017, p.976).

Contextualizar um pouco do trabalho docente, tanto no contexto anterior à pandemia, quanto a oferta do ensino a alunos especiais, de forma remota, neste prolongado período pandêmico, funciona no sentido de demonstrar que as dificuldades se acentuam ainda mais com o distanciamento social, com o foco apenas no conteúdo e na entrega de "produtos", ou seja, de atividades que os alunos devem entregar em suas escolas. Cabe ressaltar que:

A metodologia de ensino inclusivo deve ser capaz de garantir que o aluno se sinta motivado para enfrentar a escola e participar das atividades na sala de aula, que possua qualidade curricular e metodológica, que identifique barreiras de aprendizagem e planeje formas de removê-las, com o objetivo de que cada aluno seja contemplado e respeitado em seu processo de aprendizagem. (Arnal \& Mori, 2009, p. 10).

O AEE não se limita ao espaço físico da Sala de Recursos Multifuncionais. Por isso, em tempos de pandemia, pode e deve ser oferecido aos estudantes que dele necessitem, possibilitando atividades pedagógicas remotas ricas em oportunidade para que cada um aprenda de acordo com suas possibilidades. Destaca-se, também, o apoio que deve ser dado aos professores 
da sala de aula comum na escolha das atividades curriculares que serão enviadas. Assim, as barreiras atitudinais, tecnológicas e comunicacionais, que se fazem tão presentes na realidade da maioria dos estudantes com deficiência, transtorno do espectro autistas e altas habilidades, serão minimizadas ou até mesmo eliminadas.

Ainda que os espaços adequados sejam fundamentais para a realização das atividades diretamente com os alunos de inclusão, a pandemia impossibilitou que estas atividades fossem feitas de maneira presencial. Além disso, questões semelhantes eram cobradas em avaliações anuais, todas realizadas a distância e enviadas para os e-mails dos responsáveis. Para tanto, Schneider e Marin (2020) ratificam a necessidade de metodologias e constância nas atividades de inclusão.

O processo de inclusão também não pode ser esquecido, mesmo com a pandemia e com as crianças distantes umas das outras, é muito importante que o docente continue mediando e propondo atividades que integram e incluam a turma como um todo. A partir dessa integração e envolvimento proposto pelos professores em suas atividades, é importante mostrar para os alunos que as diferenças existem em todas as comunidades e nas mais diversas situações e que tendo sensibilidade e empatia a inclusão escolar e a inclusão social é possível, mesmo em momentos que estejam afastados fisicamente (Schneider \& Marin, 2020, p.5)

Percebeu-se que os espaços multifuncionais fazem diferença no aprendizado do aluno de inclusão por diversos aspectos emocionais, tais como a empatia, o empenho, o auxílio lado a lado, enquanto a distância dificultava esse acesso, fora a conjuntura emocional e o apoio que o aluno necessita ter dentro de casa. Como tal, afirma Cury:

A manutenção do vínculo afetivo e social do estudante com deficiência com o profissional da educação especial, professores da educação básica e colegas de sala de aula, é um fator importante a ser considerado durante este período de pandemia. Deve-se, dentro do possível, manter uma rotina regular (Cury, s/a, p..5).

Ainda que os resultados possam ser conflitantes devido a situações incontroláveis por parte da escola, o acompanhamento do aluno de inclusão não deixou de existir e se mostrou minimamente eficaz com o uso de ferramentas digitais, tais como jogos, quizzes, slides e os exercícios objetivos. Como se sabe, a escrita pouco foi trabalhada resultante da dificuldade de acompanhamento destes alunos, porém, com as estratégias tríplice - conteúdo, exercício e ludicidade por meio das plataformas, mensurou-se uma aprendizagem mínima dos conteúdos do ano letivo de 2020.

Além dos espaços adequados para o aluno de inclusão, Cardozo; Santos (2020) citam, em artigo já referenciado, como é necessário o professor de AEE também se sensibilizar e realizar a inter relação entre aluno e família, uma vez que, devido às crenças limitantes e do ainda recorrente preconceito, os responsáveis não aceitam a condição do aluno, o que torna o processo ainda mais alarmante durante a pandemia. Logo, citam "[...] ao ter esta construção interrompida, se torna fundamental encontrar mecanismos para que o professor possa pensar e organizar seu planejamento de forma a contemplar a realidade do seu aluno."(Cardozo; Santos, 2020, p.46.199).

\section{Considerações Finais}

Conforme foi possível observar, o ensino remoto impôs-se inevitavelmente no contexto da pandemia da COVID-19. A ausência de políticas públicas para o território nacional, além de denunciar o grave descaso com a educação de crianças e adolescentes brasileiro, também revela a indiferença do atual governo para com a sua população. O ensino remoto, embora tenha sido um socorro, até o presente momento, uma forma de manter o seguimento de um ano letivo, acentuou as desigualdades entre os alunos das escolas públicas, mas não apenas destes, uma vez que os alunos da educação especial também passaram a ver suas dificuldades multiplicadas.

Em pesquisa, sobre o ensino remoto emergencial e suas implicações na prática pedagógica, realizada por Rondini, 
Pedro e Duarte (2020) observa-se que, as dificuldades que já eram vivenciadas pelos professores, na modalidade presencial, mas que, em certa medida, se agravaram no contexto do ensino remoto. Não bastasse todas essas dificuldades já existentes, "os alunos terão de enfrentar um sistema de educação que não tem estrutura suficiente para ampará-los frente a essa nova realidade" Avelino e Mendes (2020, p. 57).

As diretrizes, as metodologias, as estratégias educacionais para o período pandêmico ficaram a cargo dos estados e dos municípios. Até então, se tem notado um grande empenho e um esforço enorme das escolas, ou seja, das equipes escolares para que as ações adotadas para o ensino remoto cheguem até os alunos e que as atividades sejam realizadas por eles.

Tanto a rede pública como a privada têm enfrentado desafios com os quais ficaram ainda mais evidentes e difíceis de lidar. As estratégias do ensino remoto exigem de alunos, desde os mais pequenos até os adolescentes do ensino médio, uma postura autônoma de maior comprometimento com os estudos. Isso exige dos alunos uma maturidade que a grande maioria deles não possui, o que se agrava quando se trata de alunos especiais, uma vez que eles, quase sempre precisam de um atendimento individualizado, personalizado, com a presença muita das vezes de um profissional que os acompanha/assiste.

Observou-se também, que o ensino remoto frente à necessidade de manter garantidos os direitos à inclusão, alargou o campo das dificuldades dos professores, se antes da pandemia, a formação do professor em atendimento ao aluno especial, já era uma situação indispensável, agora ela é muito maior, pois este mesmo profissional continua sua empreitada no formato remoto, valendo-se de tecnologias as quais quase sempre, ele apresenta alguma dificuldade de uso. As distâncias podem alargar-se em muito, considerando-se, por exemplo, os alunos de TEA, que são indivíduos que têm deficiências marcantes na comunicação social, conforme aponta (Rossi, 2020, p. 23).

Outro fator não menos relevante, ao contrário, preocupante, é que as estratégias durante o ensino remoto, tem tido como foco principal o conteúdo e as atividades, ou seja, o produto a ser entregue na escola, ao professor, com o objetivo de registar a participação do aluno e, em dados momentos atribuir-lhes nota, o foco do processo de ensino aprendizagem deveria ser o aluno, resta saber se em algum momento do retorno ao presencial haverá espaço para o aluno, principalmente aos alunos especiais.

Nunes e Dutra 2020 p.15 destacam o quanto é necessário que o atendimento aos alunos do AEE, durante o período remoto, requer reflexão, para a construção eficiente dos recursos e instrumentos pedagógicos individuais, bem como, o quanto é fundamental o contato diário, não apenas com os alunos, mas com seus familiares, de modo a garantir que todos sejam atendidos com qualidade, em especial nesse período, segundo as especificidades de cada um.

Muito se tem ainda a acrescentar a respeito dos espaços ocupados pelos alunos especiais no cenário da pandemia do COVID-19. Seriam estes espaços ressignificados nas residências dos alunos quando a escola se vê interditada por este problema de saúde pública? A exclusão voltou a ser predominante, tendo o ensino híbrido como alternativa para evitar que os alunos regulares perdessem aula? Neste contexto, os alunos especiais estão recebendo a atenção necessária para o desenvolvimento das suas atividades? Estas são perguntas norteadoras de outros projetos de pesquisa que virão, para que, assim, encontremos uma estratégia válida inclusiva a respeito dos alunos especiais.

\section{Referências}

Albuquerque, E. T. (2020). TDAH, TPAC, Transtornos $x$ dificuldades de aprendizagem: Compreensão para uma prática pedagógica com qualidade e equidade. Trabalho de Conclusão de Curso apresentado à Comissão de Avaliação de Trabalhos Científicos da Divisão de Ensino da Escola de Formação Complementar do Exército, como exigência parcial para a aprovação no Curso de Aperfeiçoamento Militar. Santa Catarina. https://bdex.eb.mil.br/jspui/bitstream/123456789/8532/1/CAM_QCO_2020_CapElisangela.pdf

Arnal, L. S. P. \& Mori, N. N. R. (2009). Educação Escolar Inclusiva: a prática nas salas de recursos. In: Manzini, E. J. et. al. Procedimentos de Ensino e Avaliação em Educação Especial (pp.8 - 25). ABPEE.

Avelino, W. F. \& Mendes, J. G. (2020). A realidade da educação brasileira a partir da COVID-19. Boletim de Conjuntura, Boa Vista. 2(5), 56-62. https://revista.ufrr.br/boca/article/view/AvelinoMendes/2892. 
Brasil. Lei n ${ }^{\circ}$ 12.764, de 27 de dezembro de (2012). Institui a Política Nacional de Proteção dos Direitos da Pessoa com Transtorno do Espectro Autista; e altera o $§ 30$ do art. 98 da Lei n. 8.112, de 11 de dezembro de 1990. Diário Oficial da União: seção 1, Brasília, DF, ano 149, 2012. p.3. http://www.planalto.gov.br/CCivil_03/_Ato2011-2014/2012/Lei/L12764.htm.

Brasil. Lei $n^{\circ} 13.146$ de 6 de julho de (2015). Institui a Lei Brasileira de Inclusão da Pessoa com Deficiência (Estatuto da Pessoa com Deficiência). planalto.gov.br/ccivil_03/_ato2015-2018/2015/lei/113146.htm.

Brasil. Lei $\mathrm{n}^{\circ} 14.040$ de 18 de agosto de (2020). Estabelece normas educacionais excepcionais a serem adotadas durante o estado de calamidade pública reconhecido pelo Decreto Legislativo $\mathrm{n}^{\circ}$ 6, de 20 de março de 2020; e altera a Lei $\mathrm{n}^{\circ} 11.947$, de 16 de junho de 2009 , 2020a. https://normativasconselhos.mec.gov.br/normativa/view/CNE_PAR_CNECPN52020.pdf?query=supervis $\mid l u 00 e 30$

Brasil. Parecer CNE/CP n 5 de 28 de abril de (2020). Reorganização do Calendário Escolar e da possibilidade de cômputo de atividades não presenciais para fins de cumprimento da carga horária mínima anual, em razão da Pandemia da COVID-19. Conselho Pleno. Conselho Nacional de Educação: Distrito Federal/DF

Cardozo, P. R. \& Santos, A. M. (2020). A criança com TEA: o ingresso no ensino fundamental em meio à pandemia. Braz. J. of Develop., 6, 46193-46201 jul. 2020. ISSN 2525-8761. https://www.brazilianjournals.com/index.php/BRJD/article/view/13113/11022.

Cury, C. R. J., Ferreira, L. A. M, Ferreira, L. G. F. \& Rezende, A. M. S. S. (2020). O aluno com deficiência e a pandemia. https://freemind.com.br/blog/wpcontent/uploads/2020/07/O-aluno-com-defici\%C3\%AAncia-na-pandemia-I.pdf.

De Sousa Oliveira, Eleilde et al. (2020). A educação a distância (EaD) e os novos caminhos da educação após a pandemia ocasionada pela Covid-19. Brazilian Journal of Development, 6, 52860-52867.

Freitas, S. O. \& Trotta, L. M. (2020). Acessibilidade tecnológica para os alunos da rede privada e pública durante a pandemia. Revista Carioca de Ciência, Tecnologia e Educação. https://recite.unicarioca.edu.br/rccte/index.php/rccte/article/view/137/159.

Loureiro, A., Rodrigues, E. P. \& Mattar, J. (2020) Educação online em tempos de pandemia - desafios e oportunidades para uma escola inclusiva. Revista Interações, 16.

Neta, A.S.O., Nascimento, R.M. \& Falcão, G.M.B. (2020). A educação dos estudantes com deficiência em tempos de pandemia de covid-19: a invisibilidade dos invisíveis. Revista Interações, 16. https://revistas.rcaap.pt/interaccoes/article/view/21070.

Nunes, R. C. A., \& Dutra, C. M. (2020). Ensino remoto para alunos do Atendimento Educacional Especializado. Research, Society and Development, 9(11), e64291110060. https://doi.org/10.33448/rsd-v9i11.10060

Pasian, M. S. Mendes, Gonçalves, E. \& Cia, Fabiana. (2020). Atendimento educacional especializado: aspectos da formação do professor. https://www.scielo.br/j/cp/a/VNYB7zVGB4YM33xLLmyG4tv/?lang=pt.

Pereira A. S. et al. Metodologia da pesquisa científica. UFSM, 2018. https://repositorio.ufsm.br/bitstream/handle/1/15824/Lic_Computacao_MetodologiaPesquisa-Cientifica.pdf?sequence $=1$.

Rondini, C. A., Pedro, K. M., \& Duarte, C. dos S. (2020). Pandemia do covid-19 e o ensino remoto emergencial: mudanças na práxis docente. Educação, 10(1), 41-57. https://doi.org/10.17564/2316-3828.2020v10n1p41-57

Rossi, Cláudia Maria Soares. (2020). Transtornos globais de desenvolvimento e específicos de aprendizagem: Arcos, 2020. Apostila (Pós-Graduação em Docência) --Instituto Federal de Minas Gerais.

Schneidder, J.A. \& Marin, E. B. (2020). Os desafios da didática pedagógica na perspectiva da educação especial durante a pandemia. XXI Encontro Nacional de Educação. I Seminário Internacional de Estudo e Pesquisa em Educação nas Ciências, 2020. https://publicacoeseventos.unijui.edu.br/ind ex.php/enacedesiepec/article/view/18689/17453

Silva, K. W. da, BIns, K. L. G., \& Rozek, M. (2020). A educação especial e a covid-19: aprendizagens em tempos de isolamento social. Educação, 10(1), 124-136. https://doi.org/10.17564/2316-3828.2020v10n1p124-136.

Souza, Flavia Faissal de, \& Dainez, Débora (2020). Educação Especial e Inclusiva em tempos de pandemia: o lugar de escola e as condições do ensino remoto emergencial. Práxis Educativa (Brasil). https://www.redalyc.org/articulo.oa?id=89462860084

Torres, Josiane Pereira; Borges, Adriana Araújo Pereira. Educação especial e a Covid-19:o exercício da docência via atividades remotas. Revista Retratos da Escola, Brasília, 14, 824-841. http://retratosdaescola.emnuvens.com.br/rde/article/view/1205/pdf. 